\title{
Gender Inequality and Resource Sharing: Evidence from Rural Nicaragua
}

Citation for published version (APA):

D'Exelle, B., \& Riedl, A. (2018). Gender Inequality and Resource Sharing: Evidence from Rural Nicaragua. Journal of Development Perspectives, 2(1-2), 62-87. https://doi.org/10.5325/jdevepers.2.1-2.0062

Document status and date:

Published: 01/01/2018

DOI:

10.5325/jdevepers.2.1-2.0062

Document Version:

Publisher's PDF, also known as Version of record

Document license:

Taverne

Please check the document version of this publication:

- A submitted manuscript is the version of the article upon submission and before peer-review. There can be important differences between the submitted version and the official published version of record.

People interested in the research are advised to contact the author for the final version of the publication, or visit the DOI to the publisher's website.

- The final author version and the galley proof are versions of the publication after peer review.

- The final published version features the final layout of the paper including the volume, issue and page numbers.

Link to publication

\footnotetext{
General rights rights.

- You may freely distribute the URL identifying the publication in the public portal. please follow below link for the End User Agreement:

www.umlib.nl/taverne-license

Take down policy

If you believe that this document breaches copyright please contact us at:

repository@maastrichtuniversity.nl

providing details and we will investigate your claim.
}

Copyright and moral rights for the publications made accessible in the public portal are retained by the authors and/or other copyright owners and it is a condition of accessing publications that users recognise and abide by the legal requirements associated with these

- Users may download and print one copy of any publication from the public portal for the purpose of private study or research.

- You may not further distribute the material or use it for any profit-making activity or commercial gain

If the publication is distributed under the terms of Article $25 \mathrm{fa}$ of the Dutch Copyright Act, indicated by the "Taverne" license above, 
Gender Inequality and Resource Sharing: Evidence from Rural Nicaragua Author(s): Ben D’Exelle and Arno Riedl

Source: Journal of Development Perspectives, 2018, Vol. 2, No. 1-2 (2018), pp. 62-87

Published by: Penn State University Press

Stable URL: https://www.jstor.org/stable/10.5325/jdevepers.2.1-2.0062

\title{
REFERENCES
}

\author{
Linked references are available-on JSTOR for this-article: \\ https: / /ww .jstor.org/stable/10.5325/jdevepers.2.1-2.0062?seq=1\&cid=pdf- \\ reference\#references_tab_contents \\ You may need to log in to JSTOR to access the linked references.
}

JSTOR is a not-for-profit service that helps scholars, researchers, and students discover, use, and build upon a wide range of content in a trusted digital archive. We use information technology and tools to increase productivity and facilitate new forms of scholarship. For more information about JSTOR, please contact support@jstor.org.

Your use of the JSTOR archive indicates your acceptance of the Terms \& Conditions of Use, available at https://about.jstor.org/terms 


\title{
Cender Inequality and Resource Sharing: Evidence from Rural Nicaragua
}

\author{
BEN D'EXELLE AND ARNO RIEDL
}

\begin{abstract}
Gender inequality in access to resources remains persistent in rural areas in developing countries. To better understand the mechanisms responsible for gender inequality, we start from the observation that access to resources in rural villages is largely determined by within-village resource sharing, which is embedded in social networks. It is therefore important to study the influence of gender on resource sharing while taking into account the social networks of men and women. To do so, we combine data from a distribution experiment and a network survey in rural Nicaragua. We find that sharing is higher among friends and that women have fewer friends than men. Men share more than women and do not discriminate against women, while women share less with men. These results are robust to controls for friendship ties and gender differences in the reporting of these ties. We attribute these results to the gendered division of labor.
\end{abstract}

\begin{abstract}
Acknowledgments: The research documented in this article was financed by the Oesterreichische Nationalbank (project number 11429), VLIR-UOS, and IOB-UA. We thank participants in workshops, seminars, and conferences in Utrecht, Rome, Berlin, Nijmegen, Maastricht, and Norwich for their valuable comments. We also benefited from comments on an earlier version of this article by Saurabh Arora, Rebecca Blank, Vincent Buskens, Simon Gächter, Jean Hagenbach, Matt Jackson, and Michael Woolcock. We also thank Guy Delmelle, Ligia Gómez, Miguel Alemán, Francisco Pérez, Selmira Flores, and Alfredo Ruíz for interesting methodological discussions; Tania Paz Mena, Leonardo Matute, Francisco Paiz Salgado, Edna García Flores, Fátima Guevara, Silvia Martinez Arróliga and Will Tellez for support with the field work; Vanessa Castrillo and Jazmina Andino for their help in the search for sufficient coins of money; Elizabeth Campos and Manuel Bermudez of the Fondo de Desarrollo Local for offering a safe in one of their local banking offices; and the community leader Francisco Varela for his local support.
\end{abstract}

JEL Codes: C9, Z1

Keywords: resource sharing, social ties, gender, lab-in-thefield experiment, Nicaragua

doi: $10.5325 /$

jdevepers.2.1-2.0062 


\section{Introduction}

Gender inequality in access to resources and opportunities remains persistent in many domains. Lowering gender inequality is assumed to be both intrinsically valuable and instrumental in bringing about productivity gains and improved social development outcomes, including for children. This is even more the case in rural areas in developing countries where gender inequality and poverty tend to be more severe and intertwined. It is argued that tackling gender inequality in these areas has an enormous potential to reduce poverty in many ways (World Bank 2012). For example, increasing women's access to resources such as credit, fertilizer, and improved seeds would raise agricultural yields on female-controlled plots by $20-30 \%$ (Food and Agriculture Organization 2011). There is also growing evidence that resources in mothers' hands are more beneficial for children's health and nutrition than when the same resources are managed by the children's fathers (Hoddinott and Haddad 1995; Thomas 1990, 1993). Increasing women's access to resources would then tackle intergenerational poverty.

To design policies that are more effective at tackling gender inequality in rural areas in developing countries, we need to improve our understanding of the mechanisms that are responsible for the persistence of gender inequality in access to resources. We start from the observation that access to resources in these areas largely depends on resource sharing among fellow villagers, which is strongly embedded in social networks (Ligon and Schechter 2012). This implies that to identify the mechanisms that are responsible for the persistence of gender inequality in such settings, a better understanding is needed of how resources are shared among men and women, and how this interacts with the social networks of men and women.

To study these questions we surveyed almost all households in a rural village in Nicaragua and elicited the network of friendship ties of both spouses in each household. After the survey, we conducted a series of incentivized resource-sharing experiments, using so-called "dictator games." In these games "dictators" could share financial resources with randomly selected other villagers as well as nonanonymous strangers outside the village, called "recipients." Combining survey and experimental data, we explore how the gender of the dictator and the recipient influence sharing decisions. In a next step, we test whether gender effects on resource sharing work directly or indirectly through the influence of gender on the formation of friendship ties by comparing regressions with and without controls for social ties. Finally, we exploit an important feature of our data, namely that we have the perspective from both persons in a pair of villagers on their social relation. This allows us to identify whether there are any gender differences in the reporting of friendship ties, and whether it matters for the estimation of the effect of friendship ties on sharing across pairs of different gender combinations.

The results can be summarized as follows. First, we find that sharing is higher among friends and that women have fewer friendship ties within their village than men. Second, we find that men share more than women and share similarly with men and women, while women share less with men than with women. Third, these gender differences in sharing are robust to controls for friendship ties as well as potential gender differences in the reporting of these ties. We attribute the observed gender differences in friendship ties and resource 
sharing to the gendered division of labor, with women spending a larger part of their time on caring for the offspring and the management of household chores, tasks which require little mobility.

Several studies are related to ours. First, over the last two decades, there has been a burgeoning literature that uses experimental methods to study gender differences in resource sharing. Many of them used university subjects, and showed a large variety in outcomes, although contrary to our findings, none of them found women to be less generous than men. ${ }^{1}$ A growing number of studies have taken the lab to the field in developing countries, and many of them included gender controls in their analysis. The ones that used dictator games, as we do, did not find statistically significant gender effects (e.g., Ado and Kurosaki (2014) in Jakarta; Binzel and Fehr (2013) in Cairo; Gowdy et al. (2003) in Nigeria; Jakiela (2011) in Kenya; and Ligon and Schechter (2012) in Paraguay;). ${ }^{2}$ Second, another line of experimental research has developed around how sharing is influenced by social proximity (Bohnet and Frey 1999; Charness and Gneezy 2008). Some of these studies have looked at the role of real-life social ties for resource sharing. Leider et al. (2009) found a positive effect of social proximity in social networks on resource sharing among students at a U.S. university, a result replicated by Goeree et al. (2010) with teenage girls at a high school and Branãs-Garza et al. (2010) with undergraduate economics students in Spain, and recently extended to developing countries by Ligon and Schechter (2012) with villagers in rural Paraguay. ${ }^{3}$

The rest of the article is organized as follows. Section 2 describes our research design, including the social tie elicitation procedure and the procedures followed in the dictator game experiment. Section 3 presents the empirical analyses and Section 4 discusses the results and concludes.

\section{Research Design}

In this section, we describe the main elements of our research design, which consists of a survey to elicit social ties, a standard survey that captures socioeconomic characteristics, and a controlled resource-sharing experiment. We also present some theoretical considerations that we will use to structure the analyses.

1. Whereas some studies did not find any gender effect, others found that women tend to be more generous than men (see, e.g., Bolton and Katok 1995; Cox and Deck 2006; Croson and Gneezy 2009; Eckel and Grossman 1996, 1998; and Konow et al. 2008 for a survey). Evidence on the effect of the recipient's gender on the giver's decision is also mixed. Dufwenberg and Muren (2006) found that men receive less than women and Ben-Ner et al. (2004) found that if the gender of the recipient is known, women tend to give systematically less to women than to men and persons of unknown gender.

2. Dictator games have been widely used to elicit sharing preferences (see, e.g., Camerer, 2003, chapter 2). In our experiment neither the term dictator or dictator game was used.

3. Some studies have looked at gender and social pressure exerted by spouses or relatives to share income (Ashraf 2009; Jakiela and Ozier 2016). However, with decision making being private in our experimental setup, we do not expect social pressure to have any significant influence on sharing. 


\subsection{Data Collection}

Of each household in a rural village, one randomly selected spouse was invited to participate in a resource-sharing experiment. More specifically, each participant played six subsequent so-called "dictator games" with different recipients. The experimenter explained to each participant who was in the role of a dictator that (s)he would sequentially receive six small cylinder boxes, each containing 20 coins of one Córdoba, $\mathrm{c} \$$ (the Nicaraguan currency), which (s)he could (but need not) share with one other named person. For each dictator, the first recipient was a stranger-that is, an unknown but named person from another village in the region. That the stranger was named allowed dictators to know the gender of the recipient. The five subsequent recipients were randomly selected village members.

The random selection involved the dictator drawing cards out of a bag containing all 123 participants. Only after the dictator had finished the sharing decision regarding a recipient was the name of the subsequent recipient drawn. Dictators were informed of the procedures before they made any decision and, hence, knew that their maximum possible earnings would be $c \$ 120$ (USD6.70 at the time of the experiment). These potential earnings corresponded to more than two days' average income in rural Nicaragua. After explaining the instructions, participants were given the opportunity to ask questions and if we identified that (part of) the instructions were unclear, we provided additional explanations. This procedure made sure that all participants understood the instructions before making any decisions. ${ }^{4}$

We planned to conduct the experiment with all households in the village and had to make sure that the chance of contagion was minimized. Therefore, only one spouse per household was allowed to participate as a dictator, and in households with two spouses it was randomly determined which of the two was asked to participate. We did not exclude participation of the other spouse in the role of recipient, but ensured that spouses of the same household were not matched as a dictator-recipient pair.

Each dictator was made aware that, although (s)he knew the identity of the recipient, the recipient did not know and also would not be told by us who had given the money. When delivering the money to recipients, we neither revealed the identity of the dictator(s) who sent the money, nor informed them about how many dictators had participated. Also dictators did not know how many other dictators would participate. ${ }^{5}$ Dictators and recipients also did not learn anything about others' earnings. All this was known by the dictators when they made their decisions.

This one-way anonymity design provides some advantages over both a complete anonymous design, where receivers and dictators do not know each other's identity, and a full disclosure design, where receivers and dictators do know each other's identity. ${ }^{6}$ First, in contrast to complete anonymity, one-way anonymity enables dictators to take into account

4. We also considered paying out only one randomly chosen decision, but decided against it because the explanation and implementation of a randomization device would have been very time-consuming and may have also raised suspicion in our subjects who did not have any experience with economics experiments.

5. This made it very unlikely that dictators anticipated that the recipients they were matched with would receive money from other dictators.

6. For a similar design, see the one-way identification treatment of Bohnet and Frey (1999). 
real-life socioeconomic characteristics of the recipient, including gender, friendship ties, and other important factors that may influence resource sharing. ${ }^{7}$ Second, with a full disclosure design, more motives could influence sharing, such as anticipated reciprocity and sanctions, which could complicate the interpretation of the results. With our one-way anonymity design, in contrast, resource sharing should be mainly influenced (directed) by altruism, which has been shown to be one of the most important drivers of sharing in friendship relations (Leider et al. 2009). ${ }^{8}$

We organized the experiment in a decentralized way, by having Nicaraguan research assistants visiting individual participants at their homes to conduct the experiment. In doing so, we deliberately deviated from the often used protocol in lab-in-the-field experiments, where experiments are centrally conducted at a public spot. We did so for the following two reasons. First, we wanted to minimize selection bias. Organizing the experiment at a public spot would open the door for self-selection as some people are reluctant to participate in public events, which might be correlated with their generosity, gender, and number of friendship ties. Second, during such gatherings, mutual influence among participants is hard to control, and we anticipated that people's behavior would be influenced by the identity of the other participants at such an event, including their gender. ${ }^{9}$

To minimize experimenter effects due to the assistant's presence, we employed the following three precautionary measures. First, all decisions were made in full privacy. As a rule, participants went inside their house or to a separate room and were thus out of sight of the assistant when making a decision. If this was not possible, the assistant turned his or her back when the dictator was handling the coins. The dictators were also instructed not to make any comments about their decisions. Second, after having taken from the box the coins they wanted to keep, dictators had to fill the box with metal rings. This ensured that the weight of the box remained constant irrespective of the amount of coins taken out. Third, after each decision, the box was sealed with tape. The decisions were recorded by the assistants' supervisor (one of the authors) who did not have any interaction with the participants. The dictators were made aware of these procedural details before they made any decisions. ${ }^{10}$

An important aspect in controlled experiments is that participants trust the researchers. This is not necessarily guaranteed when participants have no experience with economic experiments. Therefore, to build trust, we first conducted the household and social tie survey. This ensured that the research assistants were already known to the local people when they visited them for the experiment. Another important element was the support of the well-respected local community leaders, who at the start of the field research presented our team to each household and asked people to cooperate with the research team. By conducting the

7. We could have opted for a full anonymity design in which only the gender of the recipient is revealed. However, the application of such a design in settings characterized by extreme gender inequality would likely have suffered from an experimenter demand effect. For example, it is likely that with such a design, male participants might think that we would appreciate it if they showed generosity toward women who suffer from gender inequality.

8. We cannot exclude that dictators reveal themselves to the recipients after the experiment. We will discuss the consequences of this in the discussion section.

9. For more on such social effects in lab-in-the-field experiments, see Castillo and Carter (2003).

10. For more details on the experimental instructions, refer to Appendix A. 
whole experiment in only one day, we minimized possible contagion effects. We administered debriefing questions, which showed that $94.5 \%$ of the participants did not talk about the experiment with other village members who had already participated; hence, contagion is virtually absent. In addition, the research assistants were asked to make a subjective evaluation about the participants' dedication, trust, and understanding of the experiment. We did not notice any problems that could have affected the dictators' decisions.

The experiment was organized immediately after the surveys that captured basic socioeconomic data as well as social ties with each of the spouses of the other households from the same village. For the latter, we adapted a survey method successfully employed by economic anthropologists and sociologists for mapping bounded networks. ${ }^{11,12}$ Specifically, to elicit the social ties of an interviewee, we used a stack of small cards representing all households in the village. Each card held the name(s) of the spouse(s) of a household. For each of the cards, the interviewee was first asked whether (s)he knew the household. If they knew the household, $s($ he) was asked whether (s)he had a "social relation of any kind" with (one of) the spouse(s). If the answer was affirmative, we asked the interviewee to specify which spouse (s)he had a relation with, as well as the content of that relation. The use of cards gave us an easy way to avoid any order bias in the elicitation of the ties, by reshuffling the cards at the start of every new interview. ${ }^{13}$

\subsection{Theoretical Considerations}

To structure the analysis, we use the following model. Following Andreoni and Miller (2002), we use a utility function $U_{i}\left(x, E-x ; \alpha_{i j}\right)$, which depends on the payoffs of subjects $i$ and $j$. We assume that the payoffs are directly determined by the distribution decision of player $i$ and that this decision remains unknown to $j$. Specifically, subject $i$ decides to keep $x$ out of an endowment $E$ for herself and to give the remainder $E-x$ to person $j$, to maximize their utility. The parameter $\alpha_{i j} \in[0,1]$ weighs the importance of the amount given to the recipient versus the amount kept $x$. The larger its value, the more will be given to the matched recipient. It can be seen as a measure of $i$ 's altruism and consists of two components with $\alpha_{i j}=\alpha_{i}^{0}+\alpha_{i}^{1} P_{i j}$ (cf., Leider et al. 2007). The first component represents $i$ s baseline altruism and the second measures $i$ 's directed altruism, with $P_{i j}$ being the social proximity between $i$ and $j$. It captures the idea that people tend to attribute a higher weight to the income of close others (Bohnet and Frey 1999; Charness and Gneezy 2008). In our setting, we assume that $P_{i j}=1$ if $i$ and $j$ are friends, 0 otherwise, with $\alpha_{i}^{0} \geq 0$ and $\alpha_{i}^{1} \geq 0$.

11. Bounded networks are networks with clearly defined boundaries, such as networks within villages and organizations, for which all members are surveyed. For a description of the method see, for instance, the documents section of Jean Ensminger's and Joseph Henrich's Roots of Sociality project website at http://jee.caltech.edu/files/2011/06/Social-Network-Analysis.pdf.

12. Leider et al. (2009) used an incentivized coordination game procedure to elicit friendship ties among Harvard students. We did not adopt their elicitation method as it would be too complicated for our subjects.

13. In addition to friendship relations we also captured economic relations, neighbor relations, family relations, and joint participation in social-public activities. As there is convincing evidence that resource sharing is mostly driven by proximity in friendship ties (Branãs-Garza et al. 2010; Goeree et al. 2010; Leider et al. 2009), we focus on friendship ties in this article. 
Importantly, we expect gender differences in $\alpha_{i}^{0}, \alpha_{i}^{1}$, and $P_{i j}$. First, there may be a gender difference in baseline altruism $\left(\alpha_{i}^{0}\right)$. In line with some of the experimental literature discussed above, baseline altruism may be larger for women than for men. However, the development economics literature suggests that women may get more utility out of keeping $x$ than men, which would make baseline altruism actually lower for women than for men, implying an opposite hypothesis. It has been documented that women have a stronger preference to spend resources on human capital, such as health, food-related household consumption, and their children (Dunbar et al. 2013; Hoddinott and Haddad 1995; Kennedy and Peters 1992; Phipps and Burton 1998; Thomas 1990, 1993; Yoong et al. 2012;). Such preference may make women share less than men with people outside their household.

Second, we can also expect the directed altruism component $\alpha_{i}{ }^{1} P_{i j}$ to differ between men and women. This may be due to expected differences in $P_{i j}$ if women, compared to men, are on average more socially distant from other people in their village, which in turn would make women share less with other people in their village. Women may be less socially connected with others in their village, as they tend to face more severe constraints in terms of time poverty (Blackden and Wodon 2006) and spatial mobility (Hanson 2010; Mandel 2006), both the result of the existing gendered division of labor. There may also be considerable levels of sorting on gender in social ties as identified by some empirical studies (Attanasio et al. 2012; Bastani 2007; Comola and Fafchamps 2014; Marsden 1987; Stehl et al. 2013; Wellman 2007). In addition, $\alpha_{i}^{1}$ may differ across different gender combinations. The higher mobility and time constraints that women face may make it more difficult for them to take advantage of any social ties, which might lower their importance to them. Also, same-gender ties may be more valued than mixed-gender ties, as individuals who are similar are more likely to interact with each other (for a literature review on "homophily" effects, see McPherson et al. 2001).

\section{Results}

In this section, we present the empirical results. After a description of the study location, we present the analyses, which look at potential gender effects as described in the conceptual section. We will start with a descriptive analysis of the sharing decisions, after which we employ regression analysis to look into the influence of gender and friendship ties on resource sharing. We end with some robustness tests that take account of potential gender biases in the reporting of friendship ties.

\subsection{Location}

For this study, we selected a village located in a rural area in the Northern part of the Pacific region of Nicaragua. It was purposely selected as it is representative for this area. The difficult agro-ecological conditions (dry season, irregular rainfall, low fertility of soils, etc.) make agricultural activities not very profitable in this region. Cattle breeding is one of the most lucrative economic activities because it is both an income source and an important savings instrument that enables local people to bridge the long and harsh dry season.

The village consists of 66 households of which 9 have only one spouse (i.e., divorced or widow/widower) and 57 have two spouses. This size is similar to other villages in the 
Table 1 Summary Statistics of Important Socioeconomic Characteristics

\begin{tabular}{|c|c|c|c|}
\hline & Mean/Percentage & St. Dev. & No. of Obs. \\
\hline \multicolumn{4}{|l|}{ a. Households } \\
\hline Land (percentage of owners) & 34.48 & - & 58 \\
\hline Land (mean in ha.) & 11.74 & 24.76 & 58 \\
\hline Cattle (percentage of owners) & 46.55 & - & 58 \\
\hline Cattle (mean in no. of animals) & 3.55 & 9.44 & 58 \\
\hline Wealth (index) & 0.00 & 1.75 & 58 \\
\hline \multicolumn{4}{|l|}{ b. Spouses } \\
\hline Gender (percentage male) & 49.50 & - & 109 \\
\hline Age (mean in years) & 46.05 & 14.49 & 109 \\
\hline Education (mean in years) & 4.13 & 3.59 & 109 \\
\hline Residence in village (mean in years) & 33.22 & 15.63 & 100 \\
\hline Visits to urban center (mean no. last month) & 2.07 & 3.36 & 100 \\
\hline \multicolumn{4}{|l|}{ c. Dictators } \\
\hline Gender (percentage male) & 47.37 & - & 57 \\
\hline Age (mean in years) & 44.16 & 12.78 & 57 \\
\hline Wealth (index) & -0.07 & 1.65 & 57 \\
\hline Education (mean in years) & 3.72 & 3.30 & 57 \\
\hline Residence in village (mean in years) & 32.91 & 15.40 & 57 \\
\hline Visits to urban center (mean no. last month) & 2.10 & 2.61 & 57 \\
\hline
\end{tabular}

area. Of the 123 spouses in total, 61 are male and 62 are female. We collected data on 58 households (87.9\%) and at least 100 spouses (81.3\%). Table 1 reports descriptive statistics of important socioeconomic characteristics. It indicates a pronounced diversity across households as well as spouses.

In panel (a) we observe that $34.48 \%$ of the households own land and land possession is unequally distributed, with the standard deviation being more than twice as large as the mean of 11.74 hectares. For cattle possession, the figures are similar: $46.55 \%$ of all households possess cattle, and the average number of cows per household is 3.55 with a standard deviation of 9.44. We also calculated a wealth index equal to the first factor of a maximum likelihood factor analysis using economic assets such as land, cattle, and the possession of tools/equipment which are good proxies for wealth in the region.

Panel (b) summarizes individual characteristics of spouses. Average education of spouses in the village, measured in number of years of schooling, is only slightly above 4 years with quite some variation. Another potentially important characteristic is the number of years of residence in the village, the average of which is around 33 years. The average frequency of contact with the urban center, which is important to obtain access to economic goods and services, is around 2 visits, as measured in the most recent month before our survey.

Average differences between men and women are as follows. Men are on average 5.71 years older than women ( $p=0.041$, two-sided $t$-test). This is in line with average age differences between husbands and wives in rural Nicaragua. Other differences are not statistically significant: education (average difference $=-0.74 ; p=0.290$, two-sided $t$-test), residence 


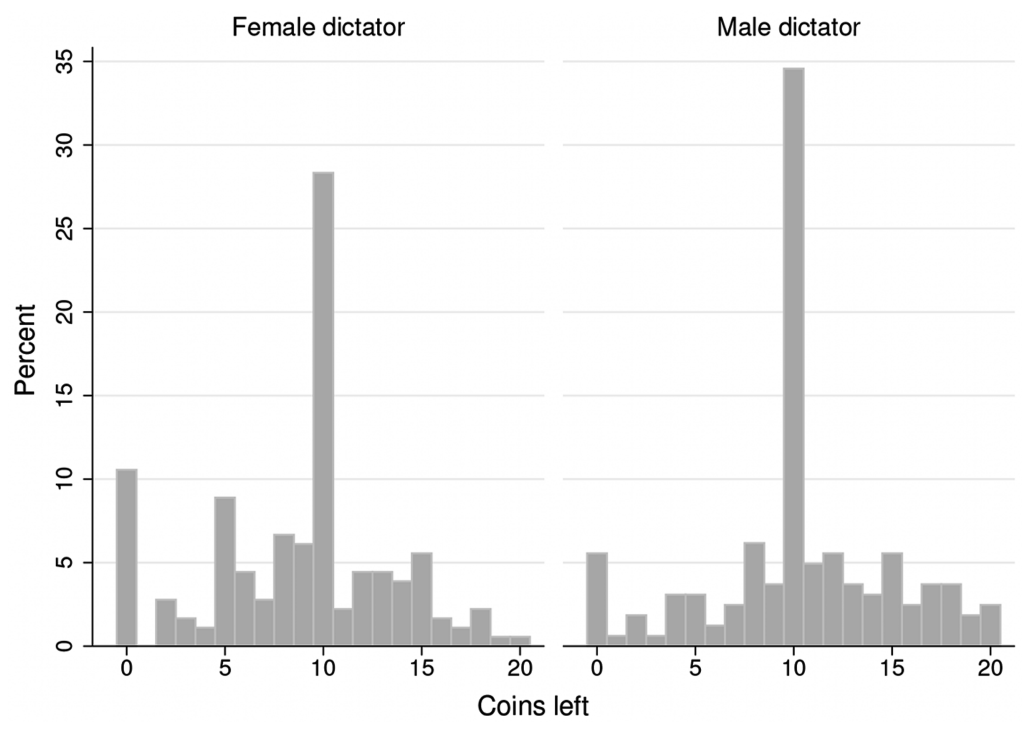

Figure 1 Resource sharing by gender of dictator.

in village (average difference $=4.76, p=0.131$, two-sided $t$-test) and visits to urban center (average difference $=1.06, p=0.117$, two-sided $t$-test).

Panel (c) presents the characteristics of the spouses who participated in the dictator game. We observe that the characteristics are very similar between panels (b) and (c), which confirms that the random selection of the sampled respondents into the experiment was done successfully.

\subsection{Descriptive Analysis of Sharing}

We start with a descriptive analysis of sharing decisions, and how they depend on the gender of the dictator and recipient. Then, we look at the role of social proximity, by studying whether it influences sharing, whether it correlates with gender, and whether its effect on sharing depends on gender.

\subsubsection{Sharing and Gender}

Figure 1 presents the distribution of coins given to the recipient (including strangers and fellow villagers), disaggregated by the gender of the dictator. For both male and female dictators we observe large variation in allocations with a dominant mode at the equal split of 10 coins. These distributions indicate that women tend to share less resources than men. On average, women leave 8.78 coins (st. dev. 4.68) and men leave 10.36 coins (st. dev. 4.65) to the recipient.

Intriguingly, there is a relatively large share of decisions in which dictators leave more than $50 \%$ of the coins to the recipient. Two factors may account for this generous behavior. First, before making a decision, dictators were given the name of the recipient. ${ }^{14}$ Second,

14. Bohnet and Frey (1999) and Charness and Gneezy (2008) showed that revealing the identity of the recipient significantly increases dictator giving. Henrich et al. (2005) also observed proposals of more than $50 \%$ in ultimatum game experiments in some of their investigated small-scale societies. 

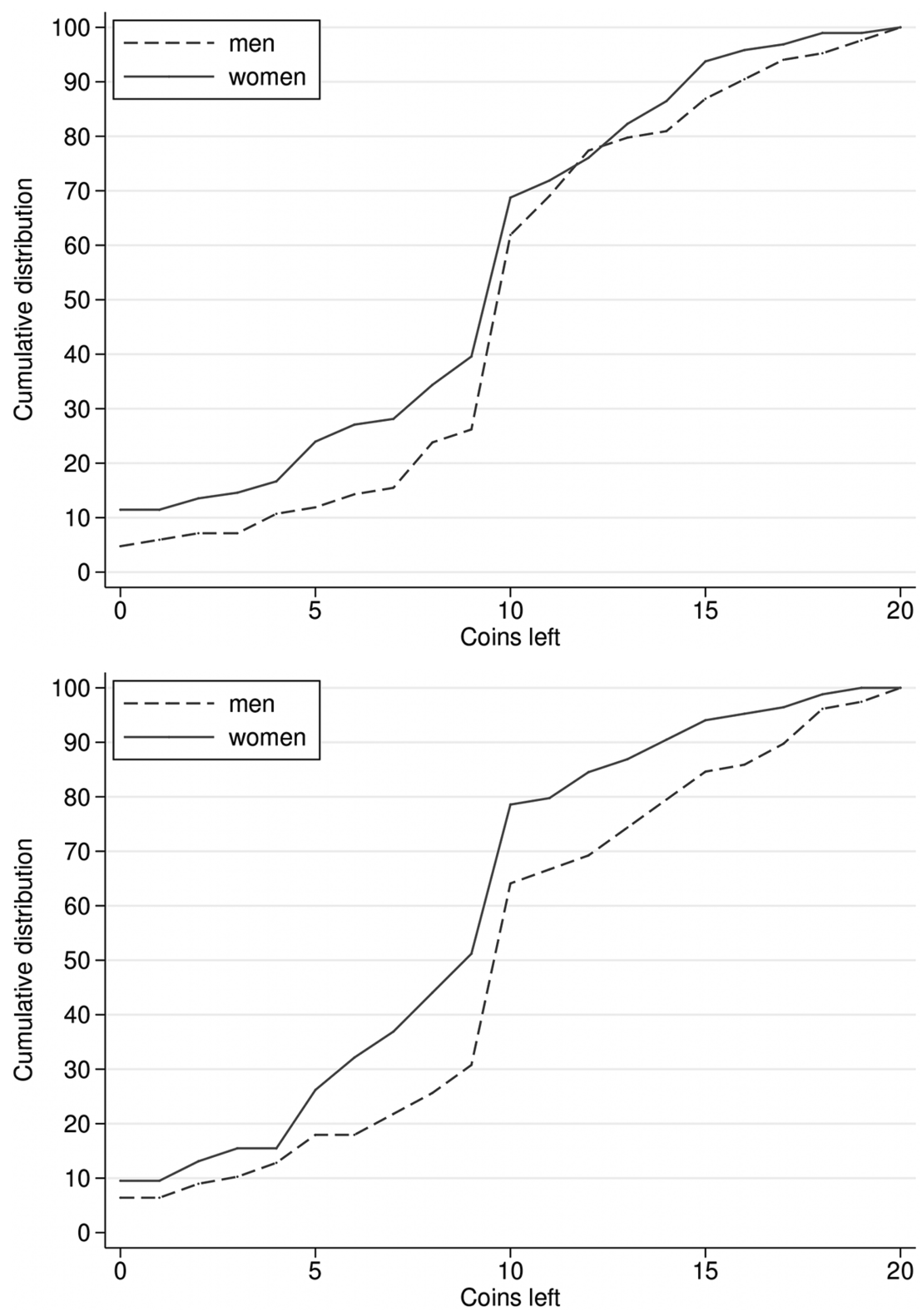

Figure 2 Resource sharing by gender of dictator and recipient.

as in most small-scale societies, in this village most people know each other (based on our social ties data, in $93.5 \%$ of all possible ties the other was known).

In a next step, we take the gender of the recipient into account. Figure 2 shows the cumulative distributions of resource sharing of male and female dictators for same-gender pairs (panel (a)) and different-gender pairs (panel (b)). These distributions again indicate that women tend to share less than men do, and that the differences become stronger when the dictator and recipient have different genders, as a comparison of both panels shows. 
Table 2 Sharing by Gender Combination

\begin{tabular}{lllllll}
\hline & \multicolumn{2}{c}{ Women } & & \multicolumn{2}{c}{ Men } & \\
\cline { 2 - 3 } & Mean & $N$ & & Mean & $N$ & p-value \\
\hline a. All pairs & 9.09 & 96 & & 10.39 & 84 & 0.204 \\
Same gender & 8.42 & 84 & & 10.33 & 78 & 0.117 \\
Different gender & & & & & \\
b. Same village pairs & 9.19 & 80 & & 10.55 & 67 & 0.190 \\
Same gender & 8.16 & 70 & & 10.63 & 68 & $0.042^{* *}$ \\
Different gender & & & & & & \\
\hline
\end{tabular}

Notes: Wald-test with standard errors corrected for multiple decisions per dictator, by using a robust (linearization) variance estimator. ${ }^{* * *},{ }^{* *},{ }^{*}$ indicate two-sided significance levels at 1,5 , and $10 \%$, respectively.

To test whether average sharing differs between male and female dictators, and whether it depends on the gender of the recipient, we use a two-tailed Wald-test. Table 2 presents the results. Using all dictator-recipient pairs (panel (a)), we find that male dictators tend to share more than female dictators, in both same-gender and different-gender pairs. Based on the $p$-values, however, we cannot reject the hypothesis of no difference in sharing. Using pairs of dictators and recipients who live in the same village, we find that the difference in sharing between men and women is statistically significant with different-gender pairs.

\subsubsection{The Role of Social Proximity}

The fact that we only find significant gender differences in sharing with pairs in the same village suggests that the effect of gender interacts with social proximity between dictator and recipient. Social proximity differs depending on whether dictator and recipient live in the same village, and if they live in the same village, whether they have a friendship tie. While the first source of variation is exogenously determined by our experimental design, variation in friendship ties is endogenous, and may be correlated with gender.

As discussed before, there are two important ways in which social proximity can interact with gender. First, if social proximity influences sharing - as several studies have demonstrated-and at the same time correlates with gender, gender differences in sharing may be caused by gender differences in social proximity. For example, women may be less generous than men if they have fewer social ties with other people in their village than men. Second, the influence of social proximity on sharing itself may depend on the gender of the dictator and recipient. To get an idea of whether our data support these mechanisms, we will look at each of these conditions. More specifically, we will have a closer look at whether: (1) social proximity influences sharing; (2) social proximity correlates with gender; and (3) the effect of social proximity on sharing depends on gender.

In a first step, we study whether social proximity, via social ties and living in the same village, influences sharing. Overall, we gathered social ties data for 100 of the 123 spouses (81.3\%). ${ }^{15}$ As explained before, we asked each spouse whether (s)he had a friendship tie with the other spouse.

15. Our success rate is slightly higher than those of Goeree et al. (2010) and Leider et al. (2009), who report success rates of $77 \%$ and $71 \%$, respectively. Of the missing 23 spouses, only two refused to participate and 21 were not present in the village when we conducted the study. 


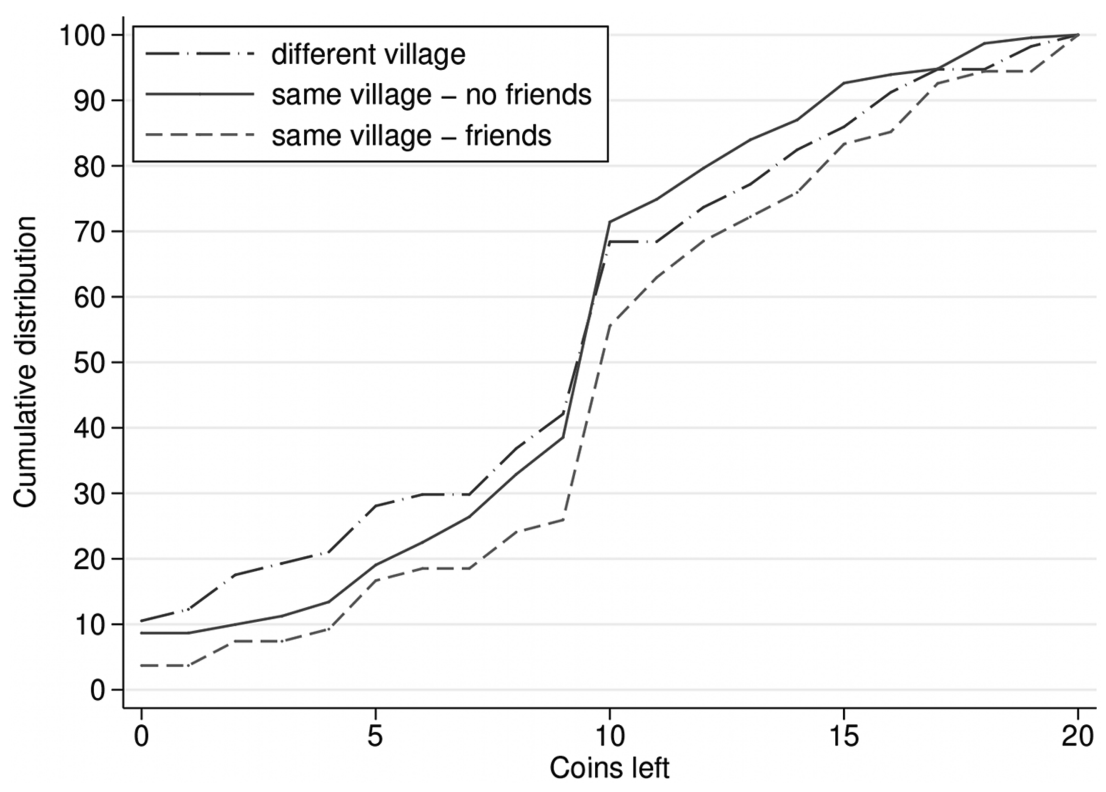

Figure 3 Sharing by social proximity.

Figure 3 shows how the distribution of coins left to the recipient varies across different levels of social proximity. We observe that the distribution of coins left to friends is skewed toward higher generosity compared to the distributions of coins left to nonfriends who live in the same village and to strangers.

In a second step, we test whether social proximity via social ties correlates with gender. Table 3 reports the frequency of friendship ties. Panel (a) presents these frequencies as a proportion of the total number of potential ties. Reported friendship ties among men are more common than among women (22.82\% and $7.50 \%$, respectively), and based on two-tailed adjusted Wald-test, the difference is statistically significant (two-sided $p=0.000$ ). ${ }^{16}$ Friendship ties among men are also more common than mixed-gender ties as reported by men (6.47\%), which is again statistically significant (two-sided $p=0.000$ ). The frequency of friendship ties among women is similar to the frequency of mixed-gender ties as reported by women (two-sided $p=0.188$ ).

In a final step, we test whether the influence of social proximity depends on the gender of the dictator. Table 4 presents the results. In panel (a) we compare average sharing between recipients from a different village (strangers) and recipients from the same village who are nonfriends. Differences are not statistically significant. This is also the case when we disaggregate by the gender of the dictator. Comparing average sharing between recipients who are friends and nonfriends from the same village (panel (b)) we only find a difference for male dictators, which is statistically significant at the $5 \%$ level. Male dictators share on average 12.95 coins with friends and 10.15 with nonfriends. Finally, comparing average sharing

16. Standard errors in this test is corrected for multiple responses per ego, by using a robust (linearization) variance estimator. 
Table 3 Summary Statistics of Reported Friendship Ties

\begin{tabular}{lrrrrc}
\hline & \multicolumn{2}{c}{$($ a) All dyads } & & \multicolumn{2}{c}{ (b) Alter reports tie } \\
\cline { 2 - 3 } \cline { 5 - 6 } & Freq. & $N$ & & Freq. & $N$ \\
\hline Men-men & $22.82 \%$ & 2,629 & & $28.38 \%$ & 444 \\
Men-women & $6.47 \%$ & 2,672 & & $11.39 \%$ & 237 \\
Women-women & $7.50 \%$ & 3,386 & & $17.54 \%$ & 228 \\
Women-men & $9.69 \%$ & 3,323 & & $17.09 \%$ & 158 \\
\hline
\end{tabular}

Table 4 Sharing by Social Proximity

\begin{tabular}{|c|c|c|c|c|c|}
\hline \multirow[b]{2}{*}{ Panela } & \multicolumn{2}{|c|}{ Stranger } & \multicolumn{2}{|c|}{ Nonfriend } & \multirow[b]{2}{*}{$p$-value } \\
\hline & Mean & $N$ & Mean & $N$ & \\
\hline All & 9.18 & 57 & 9.34 & 250 & 0.755 \\
\hline Men & 9.22 & 27 & 10.12 & 113 & 0.186 \\
\hline \multirow[t]{2}{*}{ Women } & 9.13 & 30 & 8.70 & 137 & 0.596 \\
\hline & \multicolumn{2}{|c|}{ Nonfriend } & \multicolumn{2}{|c|}{ Friend } & \\
\hline Panel b & Mean & $N$ & Mean & $N$ & $p$-value \\
\hline All & 9.34 & 250 & 11.43 & 32 & 0.152 \\
\hline Men & 10.12 & 113 & 12.95 & 21 & $0.034^{* *}$ \\
\hline \multirow[t]{2}{*}{ Women } & 8.70 & 137 & 8.27 & 11 & 0.860 \\
\hline & \multicolumn{2}{|c|}{ Stranger } & \multicolumn{2}{|c|}{ Friend } & \\
\hline Panelc & Mean & $N$ & Mean & $N$ & p-value \\
\hline All & 9.18 & 57 & 11.34 & 32 & 0.115 \\
\hline Men & 9.22 & 27 & 12.95 & 21 & $0.006^{* * *}$ \\
\hline Women & 9.13 & 30 & 8.27 & 11 & 0.724 \\
\hline
\end{tabular}

Notes: Wald-test with standard errors corrected for multiple decisions per dictator, by using a robust (linearization) variance estimator. ${ }^{* * *},{ }^{* *},{ }^{*}$ indicate two-sided significance levels at 1,5 , and $10 \%$, respectively. Nonsymmetrized friendship ties used.

between friends and strangers, (panel (c)), we again find a significant difference with male dictators (which is now statistically significant at the $1 \%$ level), but not with female dictators.

\subsection{Regression Analysis}

So far, we observed that gender differences in sharing are more pronounced among fellow villagers than among strangers. At the same time, we found substantial variation in social proximity (via friendship ties) among fellow villagers, which is correlated with gender and sharing. Because of these correlations, it is important to investigate to what extent the gender differences in sharing are mediated through gender differences in friendship ties and to what extent they represent a direct gender effect. To do so, we run a regression with the sharing decisions with fellow villagers, in which we control for the gender of the dictator and recipient, as well as whether they are friends. Using a regression framework also allows 
us to control for other confounding socioeconomic factors. More specifically, we use the following specification:

$$
Y_{i j}=\alpha+\beta \boldsymbol{X}_{i j}+e_{i j}
$$

where $Y_{i j}$ denotes the amount of coins dictator $i$ gave to village recipient $j, \boldsymbol{X}_{i j}$ denotes the vector of explanatory variables which we will discuss in detail below, and $e_{i j}$ is an error term. As each dictator performed sharing decisions regarding five different village recipients, the observations cannot be assumed to be independent. In particular, we have that $E\left[e_{i j}, e_{i k}\right] \neq$ 0 for all $k$. Further, different dictators may have been asked to make a distribution decision with the same recipient, implying that $E\left[e_{i j}, e_{k j}\right] \neq 0$ for all $k$. To correct standard errors for these dependencies, we apply clustering on both dimensions separately (for a formal discussion of this issue, see e.g., Cameron et al. 2011; Fafchamps and Gubert 2007).17

To estimate the determinants of dictators' inclination to share resources with particular village members, we use the following identification strategy. To study the effect of different gender combinations we take the allocation of resources of female dictators to male recipients as the benchmark. For the remaining dictator-recipient gender combinations, we include the dummy variables $\mathrm{F}-\mathrm{F}, \mathrm{M}-\mathrm{F}$, and $\mathrm{M}-\mathrm{M}$, where the first (second) term indicates the gender of the dictator (recipient).

We also add a variable that counts the number of coins given to the stranger (Give stranger). We do so to control for the dictators' baseline altruism. People who are generally more generous to others (i.e., irrespective of their ties with and the characteristics of the other) can be expected to have more friends and, hence, may have a higher likelihood of having a friendship relation with the recipient. This implies that to get an unbiased estimate of the effect of friendship ties, we should control for baseline altruism.

In a second model, we add further control variables that may be correlated with both gender and sharing. More specifically, we add controls for the age, education, wealth, residence in village, and visits to urban center of the dictator and the recipient separately.

In a third model, we add a dummy variable equal to one if the dictator calls the recipient a friend, zero otherwise (Friendship tie). By comparing the models with and without this variable, we can test whether gender differences in sharing with fellow villagers are due to a direct gender effect, and to what extent they are mediated via friendship ties.

Finally, in all models, we control for the decision number in the sequence of the dictators' allocation decisions and we add fixed effects for the five different assistants who visited the dictators at their homes, to control for a potential assistant bias. In this way, we also control for the gender of the experimenter, which might influence the dictators' decision in the experiment.

Table 5 presents the results of the different models. In Models 1 and 2, the coefficient of the gender combination F-F shows that women give on average between 1.107 and 1.420 coins more to women than to men. The coefficients of $\mathrm{M}-\mathrm{F}$ and $\mathrm{M}-\mathrm{M}$ show that men give on average between 1.815 and 2.038 coins more to women and between 2.141 and 2.475 coins more to men than women give to men. Note that the size of the gender effects is larger in Model 2, where we add controls for socioeconomic characteristics of the dictator and

17. For this we used the Stata code provided by Petersen (2009). 
Table 5 Determinants of Sharing with Village Recipient

\begin{tabular}{lcccc}
\hline & $(1)$ & $(2)$ & $(3)$ & $(4)$ \\
\hline F-F & $1.107^{*}$ & $1.420^{* *}$ & $1.392^{* *}$ & $1.407^{* *}$ \\
M-F & $(0.610)$ & $(0.618)$ & $(0.608)$ & $(0.599)$ \\
M-M & $1.815^{* *}$ & $2.038^{* *}$ & $2.022^{* *}$ & $2.017^{* *}$ \\
& $(0.817)$ & $(0.840)$ & $(0.839)$ & $(0.840)$ \\
Give stranger & $2.141^{* *}$ & $2.475^{* * *}$ & $2.125^{* *}$ & $2.144^{* *}$ \\
& $(0.858)$ & $(0.927)$ & $(0.896)$ & $(0.941)$ \\
Friendship tie & $0.477^{* * *}$ & $0.471^{* * *}$ & $0.478^{* * *}$ & $0.474^{* *}$ \\
& $(0.081)$ & $(0.075)$ & $(0.074)$ & $(0.074)$ \\
& & & $1.908^{* *}$ & $1.284^{*}$ \\
Constant & & & $(0.739)$ & $(0.710)$ \\
& $4.485^{* * *}$ & 2.579 & 2.336 & 2.409 \\
R2 & $(1.357)$ & $(2.561)$ & $(2.509)$ & $(2.546)$ \\
Observations & 0.422 & 0.468 & 0.484 & 0.479 \\
Controls & 282 & 270 & 270 & 270 \\
Tie & No & Yes & Yes & Yes \\
\hline
\end{tabular}

Notes: OLS regression. ${ }^{* * *},{ }^{* *},{ }^{*}$ indicate two-sided significance levels at 1,5 , and $10 \%$, respectively; robust standard errors (in parentheses) are obtained by means of two-way clustering at the level of dictators and recipients. Nonsymmetrized friendship ties used.

recipient. The results also confirm that men do not differentiate between male and female recipients. The coefficients of $\mathrm{M}-\mathrm{F}$ and $\mathrm{M}-\mathrm{M}$ are not significantly different from each other (in both models $p>0.371$, two-sided F-tests), indicating that men are equally generous to male and female recipients. This is in contrast to women, who are more generous to women than to men, as indicated by the statistically significant coefficient of F-F. Furthermore, while men are more generous to men than women are to men, men and women are equally generous to women. This is confirmed by comparing coefficients of the M-F and F-F variables (in both models $p>0.447$, two-sided F-tests).

In Model 3, where we control for the existence of a friendship relation between the dictator and recipient, we observe that the effect of a friendship relation on resource sharing with other villagers is statistically significant at the $5 \%$ level. On average, dictators give nearly 2 coins more to friends compared to nonfriends. This positive and sizeable effect of friendship ties is consistent with studies examining generosity in friendship networks among students and pupils (Branãs-Garza et al. 2010; Goeree et al. 2010; Leider et al. 2009). Importantly, the observation that the size of the coefficients of the gender combinations remains large and statistically significant with controls for social ties, indicates that there is a direct gender effect on resource sharing, which does not work through the influence of gender on friendship tie formation. ${ }^{18}$

18. In the village almost all villagers know each other: in $93.5 \%$ of all possible ties the other was known. For those dyads where the other was not known, socioeconomic differences cannot have influenced resource sharing (although gender differences might still have an effect because dictators could infer the gender of the recipient from their name). To test whether this might affect the results, we also estimate the models using only those dyads where the dictator indicated a known recipient. The results are reported in Table C.1 in Appendix C and are very similar to those discussed here. 
Table 6 Determinants of Sharing by Gender of the Dictator

\begin{tabular}{|c|c|c|c|c|c|c|}
\hline & \multicolumn{3}{|c|}{ (a) Men } & \multicolumn{3}{|c|}{ (b) Women } \\
\hline & (1) & (2) & (3) & (4) & (5) & (6) \\
\hline \multirow[t]{2}{*}{ Male recipient } & 0.186 & -0.278 & -0.143 & $-1.574^{* * *}$ & $-1.574^{* * *}$ & $-1.549^{* * *}$ \\
\hline & $(0.542)$ & $(0.544)$ & $(0.510)$ & $(0.592)$ & $(0.593)$ & $(0.568)$ \\
\hline \multirow[t]{2}{*}{ Give stranger } & $0.534^{* * *}$ & $0.557^{* * *}$ & $0.534^{* * *}$ & $0.451^{* * *}$ & $0.451^{* * *}$ & $0.459^{* * *}$ \\
\hline & $(0.103)$ & $(0.103)$ & $(0.101)$ & $(0.096)$ & $(0.095)$ & $(0.097)$ \\
\hline \multirow[t]{2}{*}{ Friendship tie } & & $2.447^{* * *}$ & $1.198^{*}$ & & -0.006 & 1.262 \\
\hline & & $(0.884)$ & $(0.630)$ & & $(1.217)$ & $(1.304)$ \\
\hline \multirow[t]{2}{*}{ Constant } & 6.671 & 6.282 & 6.919 & 5.836 & 5.837 & 5.317 \\
\hline & $(4.287)$ & $(4.094)$ & $(4.188)$ & $(4.088)$ & $(4.071)$ & $(4.265)$ \\
\hline$R^{2}$ & 0.539 & 0.571 & 0.550 & 0.492 & 0.492 & 0.499 \\
\hline Observations & 130 & 130 & 130 & 140 & 140 & 140 \\
\hline Controls & Yes & Yes & Yes & Yes & Yes & Yes \\
\hline Tie & - & non-sym. & OR-tie & - & non-sym. & OR-tie \\
\hline
\end{tabular}

Notes: OLS regression. ${ }^{* * *},{ }^{* *},{ }^{*}$ indicate two-sided significance levels at 1,5 , and $10 \%$, respectively; robust standard errors (in parentheses) are obtained by means of two-way clustering at the level of dictators and recipients. Nonsymmetrized friendship ties used.

We further investigate gender differences by running Models 1 and 2 separately for female and male dictators. The results, reported in Table 6, show that for male dictators, the coefficient of the friendship tie variable is stronger than with the pooled model and highly significant. Specifically, male dictators give on average almost 2.5 coins more to friends. In stark contrast, for female dictators, friendship ties have no effect on resource sharing. Female dictators are equally generous to friends and nonfriends. This indicates that the previously observed positive effect of friendship ties in the pooled model was driven by male dictators in the sample. The results also confirm again that women are less generous toward men.

\subsection{Robustness Tests: Gender Biases in the Reporting of Friendship Ties}

In the analysis of the influence of friendship ties on sharing, so far we ignored potential gender differences in the reporting of these ties. Women and men might differ in the reporting of friendship ties if, for example, they use different definitions of friendship. In addition, it is very common for two persons in a dyad not to coincide in the reporting of a friendship tie between them (see, e.g., Comola and Fafchamps (2014)), and men and women may differ in such discordant reporting. Both issues might bias the estimated effect of friendship ties, and thus also the direct gender effects on sharing.

We first look at the reporting of mixed-gender ties, for which we go back to Table 3 . Comparing the reporting of mixed ties by men and women, we observe that men report them equally likely as women do $(6.34 \%$ and $9.92 \%$, respectively, and two-sided $p=0.160$ of a Wald test, adjusted for multiple observations per individual). This suggests that there is no gender bias in the reporting of mixed-gender friendship ties. 
Table 7 Summary Statistics of Friendship Ties (OR-ties)

\begin{tabular}{lcc}
\hline & Freq. & $N$ \\
\hline Male-only dyads & $31.72 \%$ & 1,693 \\
Female-only dyads & $12.51 \%$ & 1,870 \\
Mixed-gender dyads & $12.95 \%$ & 3,613 \\
\hline
\end{tabular}

Second, the same table also has a panel (b) which reports the same frequencies but conditional on alter (i.e., the other person in a dyad) having reported a friendship tie. This allows us to study the extent to which two persons agree on having a friendship tie. We observe that it is very common for one person not to report a tie when the other does. Looking at same-gender dyads, we find that concordant reporting is more common among men than among women. In $28.38 \%$ of the male-male dyads in which at least one person reports a friendship tie, both persons report such a tie, while with female-female dyads, this frequency is only $17.54 \%$. Based on an adjusted Wald test, this difference is statistically significant (two-sided $p=0.021$ ). Looking at mixed-gender dyads, we observe that men tend to agree somewhat less on the ties reported by women than women agree on the ties reported by men, but that this difference is not statistically significant (11.39\% versus $17.09 \%$; two-sided $p=0.269$ of an adjusted Wald test). In sum, while we find no gender differences in the reporting of mixed-gender ties, we do find gender differences in discordant reporting, which is less frequent among men than among women and mixed-gender dyads.

To deal with discordant reporting, a common procedure is to symmetrize the social ties. More specifically, we will use OR-ties, in which we assume there is a friendship tie when at least one of both nodes in a dyad reports such a tie. ${ }^{19}$ Table 7 reports the frequencies of OR-ties by gender combination. We observe that friendship ties are more common among male-only dyads than among female-only dyads or mixed-gender dyads. Based on an adjusted Wald test, this difference is statistically significant (two-sided $p=0.000$ for each comparison). The frequency of friendship ties is not statistically different between mixed-gender dyads and female-only dyads (two-sided $p=0.644$ of an adjusted Wald test). This picture is similar to the nonsymmetrized ties, but ties are obviously more frequent with OR-ties.

To test whether the results reported in Section 3.3 are robust to using OR-ties, we run the same regressions with OR-ties instead of ties as reported by the dictator. Model 4 in Table 5 presents the regression results for the pooled sample. We observe that the effect of friendship ties remains (marginally) significant. Importantly, the gender effects are robust to the use of OR-ties. In Models 3 and 6 in Table 6, which reports the results disaggregated by the gender of the dictator, we observe that the effect of a friendship tie between the dictator and the recipient is now comparable for men and women. Finally, the negative coefficient of "Male recipient" remains robust in terms of effect size and statistical significance.

19. In doing so we follow the practices of earlier network studies (cf., Jackson et al. 2012; Leider et al. 2009). 


\section{Discussion and Conclusion}

Gender inequality in access to resources and opportunities remains persistent in many domains. In rural areas in developing countries where gender inequality tends to be more severe, access to resources is mostly determined by resource sharing by fellow villagers. To better understand the mechanisms behind gender inequality, it is therefore important to study how gender influences such resource sharing. In addition, as resource sharing in rural villages tends to be strongly embedded in social networks, it is important to take into account the social ties of men and women in such an analysis. To do so, we elicited for a rural village in Nicaragua the friendship ties among the spouses of almost all households and implemented a series of dictator games played with fellow villagers as well as strangers.

We found that women tend to share less than men, and that this difference is largest when dictator and recipient live in the same village and have different genders. We also observed that friendship ties exert a positive influence on sharing and that women have fewer friendship ties within their village than men. In addition, we found that there remains a strong direct gender effect on within-village sharing, after controlling for differences in friendship ties, with women sharing less than men and less with men than with women.

These results suggest several mechanisms that are responsible for the observed gender differences in sharing, most of which we link to the gendered division of labor in rural societies. First, women's reponsibilities to take care of health- and food-related household consumption (including for their children) could explain why they share less than men with community members outside their household. In a similar vein, if women expect men to spend resources on nonhousehold-related consumption, they may be more reluctant to share with men than with women..$^{20}$

Moreover, the gendered division of labor leads to more severe time and mobility constraints for women, compared to men (Blackden and Wodon 2006; Hanson 2010; Mandel 2006). Men tend to assume tasks that involve greater frequency of social interactions while women assume tasks that require little mobility, such as caring for the offspring and the management of the household chores. This could explain the smaller friendship networks of women compared to men. We indeed found that friendship ties among women are less common than friendship ties among men, and are equally common as mixed-gender ties. These differences in friendship ties might then influence the expected sharing of men and women, as friendship ties exert a positive effect on the willingness to share resources, as supported by our results. The time and mobility constraints that women face, as well as their responsibility to take care of household consumption, could also decrease the instrumental value of sharing with friends. This would explain why we found a weaker effect of friendship ties on sharing by women,

20. This might be strenghtened if men spend resources on alcohol or other nonproductive use, which-supported by anecdotal evidence-is very common in Nicaraguan rural villages. 
although we do not want to read too much in this result, because of the relatively small number of women with friends in our sample. ${ }^{21}$

In closing, we discuss some implications for the design of policies or programs that aim to increase women's access to resources. First, the positive effect of friendship ties on resource sharing suggests that actions that stimulate the formation of women's friendship ties with men and women could increase the expected amount of resources women receive from others in their village. Second, for policies or programs that inject new resources into rural villages via local committees or representatives (e.g., via so-called "community-based development" (CBD) schemes (Mansuri and Rao 2004), our results indicate that the gender and the networks of these entry-points could have a strong influence on the actual resource distribution among men and women. If men are used as entry points, friendship networks have a strong influence on the distribution, and women who tend to be less connected will receive a smaller share. If women distribute resources, in contrast, friendship ties would be less important, and women's tendency to share less with men means that a substantially larger share will be distributed among women.

\section{Appendix}

\section{A Experimental Instructions}

The experimental instructions are originally in Spanish; text between [ ] are instructions for the experimenter assistant.

We now ask you to participate in an experiment in which you can earn money. The amount of money you earn is yours, whatever the amount is.

Soon I will give you 20 coins of 1 Córdoba and you will be free to divide this amount between yourself and another person. For this, we use this small black box [show the box]. In this box, you will find 20 coins of 1 Córdoba [open the box and show the 20 coins]. You are allowed to take as many coins as you wish. The coins you leave in the box will be given to another person. In particular, we ask you to do the following:

1. Take the number of coins you want to keep out of the box and leave in the box the coins you want to give to the other person.

2. Refill the box with these small rings [show metal rings] and put the lid on the box. In this way, I will not be able to see how many coins you will have left in the box,

21. It should be noted that we cannot exclude the possibility that dictators revealed themselves to the recipients after our experiment and that this may have influenced their sharing decisions. Assuming that they would only approach recipients if they were generous and if they expected their claims about their sharing to be perceived as credible by the recipients, this might have strengthened the effect of friendship ties on sharing, through a mechanism of "anticipated reciprocity." More specifically, one would be more generous to people who would reciprocate the generosity. We expect this to be particularly relevant for the sharing among men who, thanks to their lower time and mobility constraints, are more able to approach fellow villagers after the experiment to enforce such reciprocity. 
nor can I get an idea about it through the weight of the box. The weight of the box will always be the same whatever the amount of coins you leave in the box.

Thereafter, we put a sticker on the box with the name of the person who will get the coins and we put some tape on it to seal the box. I will give the box to my supervisor, who waits at the car and who will bring the coins to the other person. Note that you will know the identity of the other person, whereas that other person will NOT know your identity.

I will now give you some arbitrary examples for further clarification. [Take the coins of one of the boxes and use them for the examples].

1. You have here 20 coins of 1 Córdoba. Imagine that you decide to take 2 coins out of the box. How many coins will the other person receive? (20 minus 2 equals 18)

2. I will give you another example. Imagine that you decide to take 10 coins out of the box. How many coins will the other person receive? (20 minus 10 equals 10)

3. I will give you a final example. Imagine that you decide to take 20 coins out of the box. How many coins will the other person receive? (20 minus 20 equals 0 ).

We will repeat this experiment six times. Each time, you will be able to take coins and leave coins for the other person, who will each time be a different one. Thus, I will give you six boxes of 20 coins to divide between yourself and another person. Each time, this person will be a different one. The first time you will divide the 20 coins with someone from another village in this region. You will not know this person. The other five times you will divide 20 coins with someone from your community. Once again, note that this other person will NOT know your identity.

To select the five persons of your community, I will ask you to take small cards from this bag. Each card has a different number, and each number corresponds to a different person in the community. After having taken a number, I will look up this number on a list and tell you the name of that person. Thereafter, I will give you a box with coins, so that you can decide on the number of coins you keep and how many you give to the other person. When taking this decision, I will give you privacy. You can go inside your house, [if this is not possible, say: I will turn my back so that I will be unable to know your decision; give me a signal when you are ready]. Please do not tell me the decision you will make or you have taken.

After having taken your decision and having closed the box we will seal the box, and you are not allowed any more to change your decision. Thereafter, we will draw another number from the bag and I will ask you to take the next decision. [Ask whether the participant has any questions, and clarify any doubts if needed. If there are no further questions, start with the first decision.] 


\section{B Full Models}

Table B.1 Determinants of Sharing with Village Recipient

\begin{tabular}{|c|c|c|c|c|}
\hline & (1) & (2) & (3) & (4) \\
\hline $\mathrm{F}-\mathrm{F}$ & $1.107^{*}$ & $1.420^{* *}$ & $1.392^{* *}$ & $1.407^{* *}$ \\
\hline \multirow[t]{2}{*}{$\mathrm{M}-\mathrm{F}$} & $(0.610)$ & $(0.618)$ & $(0.608)$ & $(0.599)$ \\
\hline & $1.815^{* *}$ & $2.038^{* *}$ & $2.022^{* *}$ & $2.017^{* *}$ \\
\hline \multirow[t]{2}{*}{$\mathrm{M}-\mathrm{M}$} & $(0.817)$ & $(0.840)$ & $(0.839)$ & $(0.840)$ \\
\hline & $2.141^{* *}$ & $2.475^{* * *}$ & $2.125^{* *}$ & $2.144^{* *}$ \\
\hline \multirow[t]{3}{*}{ Give stranger } & $(0.858)$ & $(0.927)$ & $(0.896)$ & $(0.941)$ \\
\hline & $0.477^{* * *}$ & $0.471^{* * *}$ & $0.478^{* * *}$ & $0.474^{* * *}$ \\
\hline & $(0.081)$ & $(0.075)$ & $(0.074)$ & $(0.074)$ \\
\hline \multirow[t]{2}{*}{ Round 2} & -0.566 & -0.542 & -0.613 & -0.600 \\
\hline & $(0.575)$ & $(0.545)$ & $(0.553)$ & $(0.524)$ \\
\hline \multirow[t]{2}{*}{ Round 3} & -0.618 & -0.604 & -0.734 & -0.550 \\
\hline & $(0.584)$ & $(0.594)$ & $(0.624)$ & $(0.598)$ \\
\hline \multirow[t]{2}{*}{ Round 4} & -0.607 & -0.455 & -0.526 & -0.436 \\
\hline & $(0.485)$ & $(0.471)$ & $(0.488)$ & $(0.467)$ \\
\hline \multirow[t]{2}{*}{ Round 5} & -0.864 & -0.745 & -0.843 & -0.694 \\
\hline & $(0.561)$ & $(0.607)$ & $(0.600)$ & $(0.611)$ \\
\hline \multirow[t]{2}{*}{ Age (dict.) } & & 0.033 & 0.036 & 0.032 \\
\hline & & $(0.042)$ & $(0.040)$ & $(0.042)$ \\
\hline \multirow[t]{2}{*}{ Age (rec.) } & & 0.027 & 0.030 & 0.030 \\
\hline & & $(0.022)$ & $(0.022)$ & $(0.022)$ \\
\hline \multirow[t]{2}{*}{ Education (dict.) } & & 0.026 & 0.004 & 0.013 \\
\hline & & $(0.131)$ & $(0.122)$ & $(0.126)$ \\
\hline \multirow[t]{2}{*}{ Education (rec.) } & & -0.019 & -0.023 & -0.025 \\
\hline & & $(0.061)$ & $(0.061)$ & $(0.062)$ \\
\hline \multirow[t]{2}{*}{ Years village (dict.) } & & -0.012 & -0.016 & -0.015 \\
\hline & & $(0.029)$ & $(0.028)$ & $(0.028)$ \\
\hline \multirow[t]{2}{*}{ Years village (rec.) } & & -0.012 & -0.014 & -0.013 \\
\hline & & $(0.015)$ & $(0.014)$ & $(0.014)$ \\
\hline \multirow[t]{2}{*}{ Urban (dict.) } & & 0.054 & 0.026 & 0.044 \\
\hline & & $(0.149)$ & $(0.140)$ & $(0.142)$ \\
\hline \multirow[t]{2}{*}{ Urban (rec.) } & & $-0.080^{*}$ & $-0.082^{*}$ & -0.077 \\
\hline & & $(0.048)$ & $(0.046)$ & $(0.048)$ \\
\hline \multirow[t]{2}{*}{ Wealth (dict.) } & & 0.235 & 0.206 & 0.206 \\
\hline & & $(0.152)$ & $(0.136)$ & $(0.147)$ \\
\hline Wealth (rec.) & & -0.085 & -0.120 & -0.124 \\
\hline \multirow[t]{3}{*}{ Friendship tie } & & $(0.076)$ & $(0.078)$ & $(0.085)$ \\
\hline & & & $1.908^{* *}$ & $1.284^{*}$ \\
\hline & & & $(0.739)$ & $(0.710)$ \\
\hline \multirow[t]{2}{*}{ Constant } & $4.485^{* * *}$ & 2.579 & 2.336 & 2.409 \\
\hline & $(1.357)$ & $(2.561)$ & $(2.509)$ & $(2.546)$ \\
\hline$R^{2}$ & 0.422 & 0.468 & 0.484 & 0.479 \\
\hline Observations & 282 & 270 & 270 & 270 \\
\hline Controls & No & Yes & Yes & Yes \\
\hline Tie & - & - & non-sym. & OR-tie \\
\hline
\end{tabular}

Notes: OLS regression. ${ }^{* * *},{ }^{* *},{ }^{*}$ indicate two-sided significance levels at 1,5 , and $10 \%$, respectively; robust standard errors (in parentheses) are obtained by means of two-way clustering at the level of dictators and recipients. Nonsymmetrized friendship ties used. 
Table B.2 Determinants of Resource Sharing by Cender

\begin{tabular}{|c|c|c|c|c|c|c|}
\hline & \multicolumn{3}{|c|}{ (a) Men } & \multicolumn{3}{|c|}{ (b) Women } \\
\hline & (1) & (2) & (3) & (4) & (5) & (6) \\
\hline \multirow[t]{2}{*}{ Male recipient } & 0.186 & -0.278 & -0.143 & $-1.574^{* * *}$ & $-1.574^{* * *}$ & $-1.549^{* * *}$ \\
\hline & $(0.542)$ & $(0.544)$ & $(0.510)$ & $(0.592)$ & $(0.593)$ & $(0.568)$ \\
\hline \multirow[t]{2}{*}{ Give stranger } & $0.534^{* * *}$ & $0.557^{* * *}$ & $0.534^{* * *}$ & $0.451^{* * *}$ & $0.451^{* * *}$ & $0.459^{* * *}$ \\
\hline & $(0.103)$ & $(0.103)$ & $(0.101)$ & $(0.096)$ & $(0.095)$ & $(0.097)$ \\
\hline \multirow[t]{2}{*}{ Age (dict.) } & -0.003 & 0.005 & -0.006 & 0.022 & 0.022 & 0.023 \\
\hline & $(0.050)$ & $(0.046)$ & $(0.048)$ & $(0.060)$ & $(0.060)$ & $(0.059)$ \\
\hline \multirow[t]{2}{*}{ Age (rec.) } & 0.037 & $0.040^{*}$ & 0.040 & 0.006 & 0.006 & 0.012 \\
\hline & $(0.028)$ & $(0.022)$ & $(0.025)$ & $(0.032)$ & $(0.030)$ & $(0.031)$ \\
\hline \multirow[t]{2}{*}{ Education (dict.) } & 0.127 & 0.099 & 0.127 & 0.042 & 0.042 & 0.011 \\
\hline & $(0.208)$ & $(0.188)$ & $(0.202)$ & $(0.133)$ & $(0.133)$ & $(0.124)$ \\
\hline \multirow[t]{2}{*}{ Education (rec.) } & 0.025 & 0.006 & 0.006 & -0.103 & -0.103 & -0.080 \\
\hline & $(0.086)$ & $(0.082)$ & $(0.087)$ & $(0.097)$ & $(0.097)$ & $(0.101)$ \\
\hline \multirow[t]{2}{*}{ Years village (dict.) } & 0.026 & 0.019 & 0.025 & -0.030 & -0.030 & -0.040 \\
\hline & $(0.032)$ & $(0.028)$ & $(0.031)$ & $(0.051)$ & $(0.050)$ & $(0.048)$ \\
\hline \multirow[t]{2}{*}{ Years village (rec.) } & 0.012 & 0.014 & 0.014 & -0.015 & -0.015 & -0.018 \\
\hline & $(0.022)$ & $(0.020)$ & $(0.020)$ & $(0.025)$ & $(0.024)$ & $(0.021)$ \\
\hline \multirow[t]{2}{*}{ Urban (dict.) } & -0.079 & -0.111 & -0.104 & 0.030 & 0.030 & 0.071 \\
\hline & $(0.174)$ & $(0.160)$ & $(0.172)$ & $(0.377)$ & $(0.381)$ & $(0.377)$ \\
\hline \multirow[t]{2}{*}{ Urban (rec.) } & $-0.109^{* *}$ & $-0.104^{* * *}$ & $-0.101^{\star \star}$ & 0.045 & 0.045 & 0.055 \\
\hline & $(0.052)$ & $(0.032)$ & $(0.042)$ & $(0.077)$ & $(0.077)$ & $(0.076)$ \\
\hline \multirow[t]{2}{*}{ Wealth (dict.) } & $0.523^{* *}$ & 0.363 & $0.508^{* *}$ & 0.212 & 0.212 & 0.189 \\
\hline & $(0.249)$ & $(0.250)$ & $(0.251)$ & $(0.189)$ & $(0.185)$ & $(0.197)$ \\
\hline \multirow[t]{2}{*}{ Wealth (rec.) } & -0.112 & $-0.161^{*}$ & -0.142 & -0.100 & -0.100 & -0.142 \\
\hline & $(0.114)$ & $(0.096)$ & $(0.096)$ & $(0.072)$ & $(0.067)$ & $(0.098)$ \\
\hline \multirow[t]{2}{*}{ Round 2} & -0.948 & -1.091 & -1.037 & -0.189 & -0.189 & -0.219 \\
\hline & $(0.819)$ & $(0.882)$ & $(0.872)$ & $(0.736)$ & $(0.731)$ & $(0.714)$ \\
\hline \multirow[t]{2}{*}{ Round 3} & -0.543 & -0.921 & -0.591 & -0.574 & -0.574 & -0.390 \\
\hline & $(0.865)$ & $(1.005)$ & $(0.890)$ & $(0.887)$ & $(0.889)$ & $(0.931)$ \\
\hline \multirow[t]{2}{*}{ Round 4} & -0.200 & -0.410 & -0.316 & -0.745 & -0.745 & -0.553 \\
\hline & $(0.620)$ & $(0.699)$ & $(0.660)$ & $(0.715)$ & $(0.720)$ & $(0.792)$ \\
\hline \multirow[t]{2}{*}{ Round 5} & -0.658 & -1.065 & -0.677 & -0.764 & -0.765 & -0.629 \\
\hline & $(0.941)$ & $(0.879)$ & $(0.941)$ & $(0.741)$ & $(0.766)$ & $(0.831)$ \\
\hline \multirow[t]{2}{*}{ Friendship tie } & & $2.447^{* * *}$ & $1.198^{*}$ & & -0.006 & 1.262 \\
\hline & & $(0.884)$ & $(0.630)$ & & $(1.217)$ & $(1.304)$ \\
\hline \multirow[t]{2}{*}{ Constant } & 6.671 & 6.282 & 6.919 & 5.836 & 5.837 & 5.317 \\
\hline & $(4.287)$ & $(4.094)$ & $(4.188)$ & $(4.088)$ & $(4.071)$ & $(4.265)$ \\
\hline$R^{2}$ & 0.539 & 0.571 & 0.550 & 0.492 & 0.492 & 0.499 \\
\hline Observations & 130 & 130 & 130 & 140 & 140 & 140 \\
\hline Controls & Yes & Yes & Yes & Yes & Yes & Yes \\
\hline Tie & - & non-sym. & OR-tie & - & non-sym. & OR-tie \\
\hline
\end{tabular}

Notes: OLS regression. ${ }^{* * *},{ }^{* *},{ }^{*}$ indicate two-sided significance levels at 1,5 , and $10 \%$, respectively; robust standard errors (in parentheses) are obtained by means of two-way clustering at the level of dictators and recipients. Nonsymmetrized friendship ties used. 


\section{Analysis with Known Dyads Only}

Table C.1 Determinants of Sharing with Village Recipient

\begin{tabular}{lcccc}
\hline & $(1)$ & $(2)$ & $(3)$ & $(4)$ \\
\hline F-F & $1.252^{*}$ & $1.599^{* *}$ & $1.562^{* *}$ & $1.582^{* *}$ \\
M-F & $(0.650)$ & $(0.631)$ & $(0.627)$ & $(0.615)$ \\
& $2.099^{* *}$ & $2.388^{* * *}$ & $2.364^{* * *}$ & $2.367^{* * *}$ \\
M-M & $(0.845)$ & $(0.883)$ & $(0.879)$ & $(0.880)$ \\
& $2.358^{* * *}$ & $2.771^{* * *}$ & $2.428^{* * *}$ & $2.451^{* *}$ \\
Give stranger & $(0.890)$ & $(0.944)$ & $(0.929)$ & $(0.966)$ \\
& $0.459^{* * *}$ & $0.450^{* * *}$ & $0.457^{* * *}$ & $0.453^{* * *}$ \\
Friendship tie & $(0.081)$ & $(0.073)$ & $(0.072)$ & $(0.072)$ \\
& & & $1.797^{* *}$ & $1.232^{*}$ \\
& & & $(0.780)$ & $(0.737)$ \\
Constant & $4.655^{* * *}$ & 3.189 & 2.938 & 2.992 \\
& $(1.283)$ & $(2.601)$ & $(2.533)$ & $(2.582)$ \\
R2 & 0.417 & 0.468 & 0.483 & 0.479 \\
Observations & 275 & 263 & 263 & 263 \\
Controls & No & Yes & Yes & Yes \\
Tie & - & - & non-sym. & OR-tie \\
\hline
\end{tabular}

Notes: OLS regression. ${ }^{* * *},{ }^{* *},{ }^{*}$ indicate two-sided significance levels at 1,5 , and $10 \%$, respectively; robust standard errors (in parentheses) are obtained by means of two-way clustering at the level of dictators and recipients. Nonsymmetrized friendship ties used. Only pairs used in which the dictator knows the recipient.

\section{Additional Analyses with OR-ties}

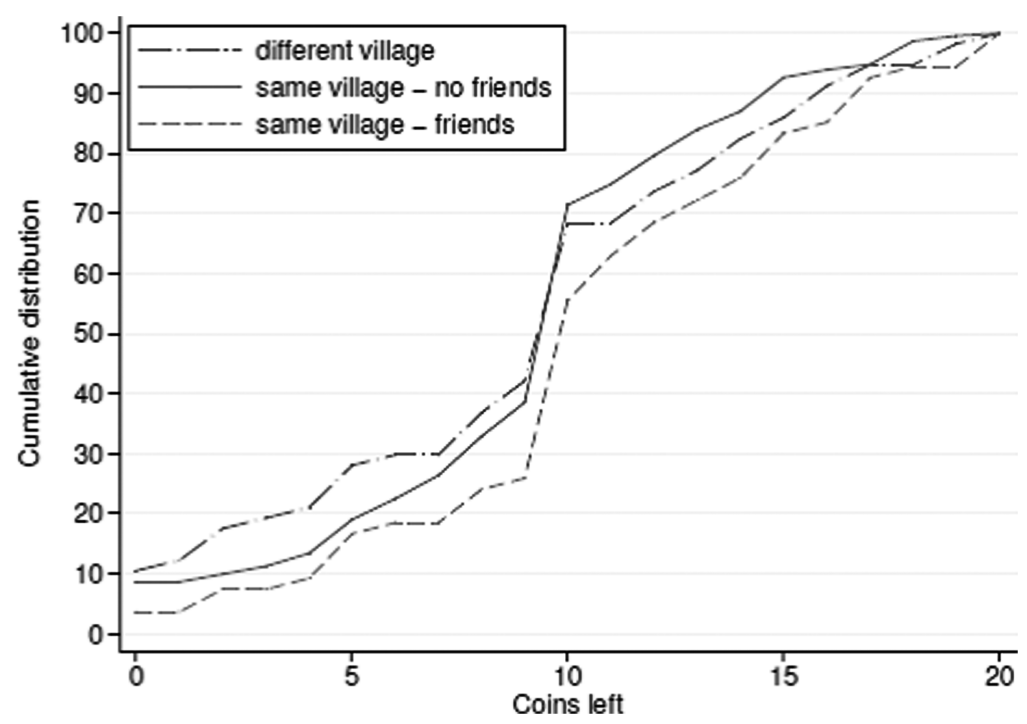

Figure D.1 Sharing by social proximity (OR-ties) 
Table D.1 Sharing by Social Proximity (OR-ties)

\begin{tabular}{|c|c|c|c|c|c|}
\hline \multirow[b]{2}{*}{ Panela } & \multicolumn{2}{|c|}{ Stranger } & \multicolumn{2}{|c|}{ Nonfriend } & \multirow[b]{2}{*}{ p-value } \\
\hline & Mean & $N$ & Mean & $N$ & \\
\hline All & 9.18 & 57 & 9.32 & 231 & 0.794 \\
\hline Men & 9.22 & 27 & 10.15 & 100 & 0.195 \\
\hline \multirow[t]{2}{*}{ Women } & 9.13 & 30 & 8.69 & 131 & 0.589 \\
\hline & \multicolumn{2}{|c|}{ Nonfriend } & \multicolumn{2}{|c|}{ Friend } & \\
\hline Panel b & Mean & $\mathrm{N}$ & Mean & $\mathrm{N}$ & $p$-value \\
\hline All & 9.32 & 231 & 10.80 & 54 & $0.099^{*}$ \\
\hline Men & 10.15 & 100 & 11.86 & 35 & $0.083^{*}$ \\
\hline \multirow[t]{2}{*}{ Women } & 8.69 & 131 & 8.84 & 19 & 0.922 \\
\hline & \multicolumn{2}{|c|}{ Stranger } & \multicolumn{2}{|c|}{ Friend } & \\
\hline Panelc & Mean & $\mathrm{N}$ & Mean & $\mathrm{N}$ & $p$-value \\
\hline All & 9.18 & 57 & 10.80 & 54 & $0.073^{*}$ \\
\hline Men & 9.22 & 27 & 11.86 & 35 & $0.013^{* *}$ \\
\hline Women & 9.13 & 30 & 8.84 & 19 & 0.858 \\
\hline
\end{tabular}

Notes: Wald-test which takes account of the multiple decisions per dictator, by using a robust (linearization) variance estimator. ${ }^{* * *},{ }^{* *},{ }^{*}$ indicate two-sided significance levels at 1,5 , and $10 \%$, respectively. OR-ties used.

\section{References}

Ado, A., and T. Kurosaki. 2014. "Motives for Sharing in Developing Countries: Experimental Evidence from Jakarta." PRIMCED Discussion Paper Series, No. 53.

Andreoni, J., and J. Miller. 2002. "Giving According to Garp: An Experimental Test of the Consistency of Preferences for Altruism." Econometrica 70 (2): 737-53.

Ashraf, N. 2009. "Spousal Control and Intra-Household Decision Making: An Experimental Study in the Philippines." American Economic Review 99 (4): 1245-77.

Attanasio, O., A. Barr, J. C. Cardenas, G. Genicot, and C. Meghir. 2012. "Risk Pooling, Risk Preferences, and Social Networks." American Economic Journal: Applied Economics 4 (2): 134-67.

Bastani, S. 2007. “Family Comes First: Men's and Women's Personal Networks in Tehran.” Social Networks 29 (3): 357-74.

Ben-Ner, A., F. Kong, and L. Putterman. 2004. "Share and Share Alike? Gender-Pairing, Personality, and Cognitive Ability as Determinants of Giving." Journal of Economic Psychology 25 (5): 581-89.

Binzel, C., and D. Fehr. 2013. "Giving and Sorting Among Friends: Evidence from a Lab-in-the-Field Experiment." Economics Letters 121 (2): 214-17.

Blackden, C. M., and Q. Wodon. 2006. "Gender, Time Use, and Poverty in Sub-Saharan Africa." World Bank Working Paper, 73.

Bohnet, I., and B. S. Frey. 1999. "The Sound of Silence in Prisoner's Dilemma and Dictator Games." Journal of Economic Behavior and Organization 38 (1): 43-57.

Bolton, G. E., and E. Katok. 1995. "An Experimental Test for Gender Differences in Beneficent Behavior." Economics Letters 48 (34): 287-92.

Branãs-Garza, P., R. Cobo-Reyes, M. P. Espinosa, N. Jiménez, J. Kovárík, and G. Ponti. 2010. "Altruism and Social Integration." Games and Economic Behavior 69 (2): 249-57. 
Camerer, C. F. 2003. Behavioral Game Theory: Experiments in Strategic Interaction. Princeton, NJ: Princeton University Press.

Cameron, A. C., J. B. Gelbach, and D. L. Miller. 2011. "Robust Inference with Multi-Way Clustering." Journal of Business and Economic Statistics 29 (2): 238-49.

Castillo, M., and M. Carter. 2003. "Identifying Social Effects with Economic Field Experiments." Working Paper, Department of Agricultural and Applied Economics, University of Wisonsin.

Charness, G., and U. Gneezy. 2008. "What's in a Name? Anonymity and Social Distance in Dictator and Ultimatum Games." Journal of Economic Behavior and Organization 68 (1): 29-35.

Comola, M., and M. Fafchamps. 2014. “Testing Unilateral and Bilateral Link Formation.” The Economic Journal 124 (579): 954-76.

Cox, J. C., and C. A. Deck. 2006. "When Are Women More Generous Than Men?” Economic Inquiry 44 (4): 587-98.

Croson, R., and U. Gneezy. 2009. “Gender Differences in Preferences.” Journal of Economic Literature 47 (2): 448-74.

Dufwenberg, M., and A. Muren. 2006. “Generosity, Anonymity, Gender.” Journal of Economic Behavior and Organization 61: 42-49.

Dunbar, G. R., A. Lewbel, and K. Pendakur. 2013. "Children's Resources in Collective Households: Identification, Estimation, and an Application to Child Poverty in Malawi." American Economic Review 103 (1): 438-71.

Eckel, C. C., and P. J. Grossman. 1996. “Altruism in Anonymous Dictator Games.” Games and Economic Behavior 16 (2): 181-91.

Eckel, C. C., and P. J. Grossman. 1998. "Are Women Less Selfish Than Men? Evidence from Dictator Experiments.” Economic Journal 108 (448): 726-35.

Fafchamps, M., and F. Gubert. 2007. “The Formation of Risk Sharing Networks.” Journal of Development Economics 83 (2): 326-50.

Food and Agriculture Organization. 2011. The State of Food and Agriculture: Women in Agriculture: Closing the Gender Gap for Development. FAO, Rome.

Goeree, J. K., M. A. McConnell, T. Mitchell, T. Tromp, and L. Yariv. 2010. “The 1/d Law of Giving.” American Economic Journal: Microeconomics 1 (1): 183-203.

Gowdy, J., R. Iorgulescu, and S. Onyeiwu. 2003. "Fairness and Retaliation in a Rural Nigerian Village." Journal of Economic Behavior \& Organization 52 (4): 469-79.

Hanson, S. 2010. "Gender and Mobility: New Approaches for Informing Sustainability." Gender, Place \& Culture 17 (1): 5-23.

Henrich, J., R. Boyd, S. Bowles, C. Camerer, E. Fehr, H. Gintis, R. McElreath, M. Alvard, A. Barr, J. Ensminger, N. S. Henrich, K. Hill, F. Gil-White, M. Gurven, F. W. Marlowe, J. Q. Patton, and D. Tracer. 2005. ''Economic Man' in Cross-Cultural Perspective: Behavioral Experiments in 15 Small-Scale Societies.” Behavioral and Brain Sciences 28: 795-815.

Hoddinott, J., and L. Haddad. 1995. "Does Female Income Share Influence Household Expenditures? Evidence from Côte d'Ivoir." Oxford Bulletin of Economics and Statistics 57 (1): 77-96.

Jackson, M. O., T. Rodriguez-Barraquer, and X. Tan. 2012. "Social Capital and Social Quilts: Network Patterns of Favor Exchange." American Economic Review 102: 1857-97.

Jakiela, P. 2011. "Social Preferences and Fairness Norms as Informal Institutions: Experimental Evidence." American Economic Review 101 (3): 509-13.

Jakiela, P., and O. Ozier. 2016. "Does Africa Need a Rotten Kin Theorem? Experimental Evidence from Village Economies." The Review of Economic Studies 83 (1): 231-68.

Kennedy, E., and P. Peters. 1992. "Household Food Security and Child Nutrition: The Interaction of Income and Gender of Household Head.” World Development 20 (8): 1077-85.

Konow, J., T. Saijo, and K. Akai. 2008. "Morals and Mores? Experimental Evidence on Equity and Equality from the US and Japan.” Technical Report, Institute of Social and Economic Research, Osaka University.

Leider, S., M. M. Mobius, T. Rosenblat, and Q.-A. Do. 2007. "How Much Is a Friend Worth? Directed Altruism and Enforced Reciprocity in Social Networks." Working Paper 13135, National Bureau of Economic Research. 
Leider, S., M. M. Möbius, T. Rosenblat, and Q.-A. Do. 2009. "Directed Altruism and Enforced Reciprocity in Social Networks." Quarterly Journal of Economics, 124 (4): 1815-51.

Ligon, E., and L. Schechter. 2012. "Motives for Sharing in Social Networks." Journal of Development Economics 99 (1): 13-26.

Mandel, J. L. 2006. "Creating Profitable Livelihoods: Mobility as a Practical and Strategic Gender Need in Porto Novo, Benin." Journal of Economic and Social Geography 97 (4): 343-63.

Mansuri, G., and V. Rao. 2004. "Community-Based and -Driven Development: A Critical Review." The World Bank Research Observer 19: 1-39.

Marsden, P. V. 1987. “Core Discussion Networks of Americans.” American Sociological Review 52 (1): $122-31$

McPherson, M., L. Smith-Lovin, and J. M. Cook. 2001. "Birds of a Feather: Homophily in Social Networks." Annual Review of Sociology 27: 415-44.

Petersen, M. A. 2009. "Estimating Standard Errors in Finance Panel Data Sets: Comparing Approaches." The Review of Financial Studies 22 (1): 435-80.

Phipps, S. A., and P. S. Burton. 1998. "What's Mine Is Yours? The Influence of Male and Female Incomes on Patterns of Household Expenditure." Economica 65 (260): 599-613.

Stehl, J., F. Charbonnier, T. Picard, C. Cattuto, and A. Barrat. 2013. "Gender Homophily from Spatial Behavior in a Primary School: A Sociometric Study." Social Networks 35 (4): 604-13.

Thomas, D. 1990. “Intra-Household Resource Allocation: An Inferential Approach." Journal of Human Resources 25 (4): 635-64.

Thomas, D. 1993. “The Distribution of Income and Expenditure Within the Household.” Annales d'conomie et de Statistique (29): 109-35.

Wellman, B. 2007. “The Network Is Personal: Introduction to a Special Issue of Social Networks." Social Networks 29 (3): 349-56.

World Bank. 2012. Gender Equality and Development: World Development Report 2012. World Bank.

Yoong, J., L. Rabinovich, and S. Diepeveen. 2012. "The Impact of Economic Resource Transfers to Women Versus Men: A Systematic Review.” Technical Report, London: EPPI-Centre, Social Science Research Unit, Institute of Education, University of London. 